\title{
Pharmaco-EEG Studies in Animals: An Overview of Contemporary Translational Applications
}

\author{
Wilhelmus H.I.M. Drinkenburga ${ }^{\mathrm{a}}$ Gé S.F. Ruigt ${ }^{\mathrm{b}} \quad$ Abdallah Ahnaou $^{\mathrm{a}}$

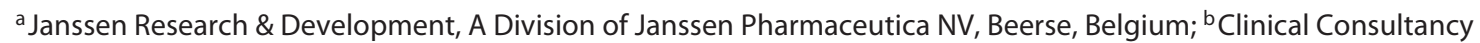 \\ for Neuroscience Drug Development, Oss, The Netherlands
}

\section{Key Words}

Electroencephalography · Pharmaco-EEG · Pharmaco-ERP .

Animal models $\cdot$ Translational research $\cdot$ Functional

biomarkers · Neuronal connectivity · Drug discovery and

development $\cdot$ Review

\begin{abstract}
The contemporary value of animal pharmaco-electroencephalography ( $p$-EEG)-based applications are strongly interlinked with progress in recording and neuroscience analysis methodology. While p-EEG in humans and animals has been shown to be closely related in terms of underlying neuronal substrates, both translational and back-translational approaches are being used to address extrapolation issues and optimize the translational validity of preclinical animal $p$-EEG paradigms and data. Present applications build further on animal p-EEG and pharmaco-sleep EEG findings, but also on stimulation protocols, more specifically pharmacoevent-related potentials. Pharmaceutical research into novel treatments for neurological and psychiatric diseases has employed an increasing number of pharmacological as well as transgenic models to assess the potential therapeutic involvement of different neurochemical systems and novel drug targets as well as underlying neuronal connectivity and
\end{abstract}

synaptic function. Consequently, p-EEG studies, now also readily applied in modeled animals, continue to have an important role in drug discovery and development, with progressively more emphasis on its potential as a central readout for target engagement and as a (translational) functional marker of neuronal circuit processes underlying normal and pathological brain functioning. In a similar vein as was done for human p-EEG studies, the contribution of animal $p$-EEG studies can further benefit by adherence to guidelines for methodological standardization, which are presently under construction by the International Pharmaco-EEG Society (IPEG).

(c) 2016 S. Karger AG, Basel

\section{Introduction}

The present paper complements the papers on human pharmaco-electroencephalography (p-EEG) in this International Pharmaco-EEG Society (IPEG) special issue with an update on contemporary animal p-EEG applications, which can be subdivided in spontaneous versus stimulation- or event-related EEG recordings. The importance of control of vigilance level, the use of pharmacological challenges, and present restrictions and chal-

\section{KARGER 125}

(c) 2016 S. Karger AG, Basel

0302-282X/16/0724-0151\$39.50/0

E-Mail karger@karger.com

www.karger.com/nps
Dr. Wilhelmus H.I.M. Drinkenburg

Janssen Research \& Development

A Division of Janssen Pharmaceutica NV

BE-2340 Beerse (Belgium)

E-Mail wdrinken@its.jnj.com 
lenges will be outlined, emphasizing the need for preclinical methodological standardization [1].

\section{Animal p-EEG Applications}

The development of more advanced analysis algorithms opened up new potential for both clinical and preclinical p-EEG applications [2], such as using the gamma band for the subgrouping or stratification of schizophrenic patients [3], for the characterization of glutamatergic drugs (e.g. $[4,5])$, in support of safety pharmacology (e.g. [6]), and for investigating neurocognition (e.g. $[7,8])$. Furthermore, EEG topography helped to reintroduce EEG by means of theta cordance as a diagnostic marker for depression [9] and as a personalized treatment-response biomarker for antidepressants $[10,11]$. EEG has also become important as a research and clinical tool in the diagnosis and treatment of developmental disorders such as attention deficit hyperactivity disorder [12] and for monitoring the functional (cognitive) decline in Alzheimer's disease (AD), also being both a preclinical and clinical functional readout of brain substrates such as loss of synaptic plasticity and impaired neuronal connectivity [13-15].

Changes in behavioral sleep and waking are the most prominent modulators of the EEG. Consequently, the confounding effects of changes in vigilance behavior should be eliminated as much as possible before analyzing the effects of a drug on the EEG of free-running animals [16]. The use of animal p-EEG effects during EEGdefined sleep for the prediction of their potential therapeutic scope and efficacy has been shown to be a valuable tool, which, however, needs careful interpretation: when compared to human p-EEG, animal p-EEG and pharmaco-sleep EEG poses specific problems, which are discussed elsewhere in this issue [17].

\section{p-EEG in Modeled Animals}

Animal p-EEG can be used very effectively to demonstrate functional antagonism of psychotropic drugs. Antagonism can be used to specifically address or model a functional disturbance or aspect of a psychiatric or neurologic disorder. For example, a scopolamine-induced delta power increase, which appears to be a hallmark of cognitive decline, is prevented by donepezil - a cognition enhancer - while the antipsychotic olanzapine 'neutralizes' the gamma power disruption induced by the psychotomimetic PCP [7]. Both academia and the pharmaceutical industry have identified and implemented event- related potentials (ERP) and quantitative time-frequency analysis of the EEG as usable and valid measurement tools or biomarkers to study the pathophysiology, phenomenology, and response to behavioral or pharmacotherapy in psychiatric and neurological disorders [1820]. ERP and EEG reliably recruit and measure the neuronal systems underlying the affective and cognitive domains that are of pathophysiological significance, such as in schizophrenia [21], AD [22], autism [23], attention disorders [24] and other neurodevelopmental and neurodegenerative brain diseases.

An intimate relationship exists between neurotransmitter tones, EEG activity, brain network communication, and functional disturbances. Earlier preclinical pEEG studies have demonstrated that different types of drugs can be separated with respect to their action on cerebral field potentials. Modulation of cholinergic, noradrenergic, serotonergic, dopaminergic, or opioidergicmediated neurotransmission elicited particular changes in EEG frequency bands which were employed to characterize the specific modulator drugs [25-29]. The investigation of brain oscillatory activities by looking at changes in frequency-specific measures can be done during a defined vigilance state, such as resting or in a given task. Synchronization of EEG oscillatory rhythms at multiple temporal and spatial scales represents a core mechanism in brain communication networks, while disturbances in neural synchrony are postulated to underlie the cognitive processing deficits in various neurological and neuropsychiatric disorders [30-36].

Oscillations within the theta frequency range are, for instance, critical to establish precise temporal interactions for the propagation and coordination of the flow of information across widely distributed neuronal networks in the subregions of the hippocampus and the entorhinal cortex [37]. Oscillatory activity in the gamma frequency range has (a) its primary generators in the cortex where subsets of inhibitory GABAergic interneuron circuits modulate glutamatergic pyramidal cell activity, (b) is involved in the establishment of synchronization with great precision in short distance local cortical networks [38], and (c) has repeatedly been shown to be associated with neurocognitive processes in normal subjects [39-43].

\section{Cholinergic Scopolamine Model}

Typical EEG alterations in AD are associated with a general slowing and decrease of alpha activity which leads to increased delta and theta activities [44]. Additionally, reduction in higher EEG frequency components in oc- 
cipital and temporal areas correlates with cognitive decline and the severity of the disease [44-49]. Altered functional and effective EEG connectivity among long-range cortical networks (i.e. frontoparietal and frontotemporal) were recently described in $\mathrm{AD}$ patients. Brain cholinergic neurons are believed to be involved in memory and cognitive dysfunction in AD. Scopolamine is a nonselective muscarinic receptor antagonist, which is widely used in preclinical as well as clinical research to simulate the EEG and cognitive abnormalities of $\mathrm{AD}$, albeit without the pathological, progressively degenerative aspects of $\mathrm{AD}$ [50]. Scopolamine impairs the activity of hippocampal and cortical fast network oscillations, leading to memory deficits combined with enhanced slow EEG oscillations in the delta frequency band [26, 51-54].

In rats instrumented with multichannel EEG electrodes, cognition enhancers such as donepezil, rivastigmine, tacrine, galantamine, and memantine, which have been approved for the symptomatic treatment of dementia, enhanced cortical slow theta $(4.5-6 \mathrm{~Hz})$ and gamma $(30.5-50 \mathrm{~Hz})$ oscillations and functional slow theta network connectivity in parieto-occipital areas, between cortical hemispheres, and in corticohippocampal networks [7]. When combined with scopolamine, the cognition enhancers attenuated the leftward shift in coherent slow delta activity combined with altered slow theta and gamma oscillations (see fig. 1 for a case study with rivastigmine), which were induced by scopolamine [7], and reduced the theta-gamma phase amplitude coupling and speed modulation of theta frequency by scopolamine [55]. Oral administration of AC-3933, a benzodiazepine receptor partial inverse agonist indicated for symptomatic treatment of $\mathrm{AD}$, resulted in the amelioration of scopolamine-induced amnesia in rats, as well as in a shift in EEG relative power (i.e. power decreases in $1-4,8-10$, and $10-12 \mathrm{~Hz}$ bands, and power increases in $4-6,6-8$ and $20-14 \mathrm{~Hz}$ bands) characteristic of procognitive cholinergic activators, such as donepezil [56]. In another study, nicotine reversed scopolamine-increased EEG theta frequency to the control level [57]. In anesthetized rats, scopolamine significantly decreased the power (by $68 \%$ ) of the brainstem stimulation-induced theta oscillation [58]. Scopolamine reduced both the rate of hippocampal pyramidal place cell discharge inside firing fields and the spatial coherence of the fields [59]. In mice, the scopolamineinduced larger slow wave activity revealed the potential role of $\alpha_{1}$ adrenergic and dopamine $D_{1}$ and $D_{2}$ receptors in the EEG desynchronized effect of modafinil [60]. Collectively, these data show that the scopolamine EEG model in the rat is a useful translational model for assay-

p-EEG Studies in Animals ing putative (acetylcholine-mediated) cognitive enhancers for the treatment of AD.

\section{Glutamatergic N-Methyl-D-Aspartate Models}

Abnormalities in functional connectivity for the gamma frequency rhythm generator have been consistently found in schizophrenic patients, in which failure in gamma oscillatory synchrony seems to be a specific functional component underlying the cognitive deficit and other symptoms of the disorder [61, 62]. Clinical reports have described complexity in gamma oscillatory response in schizophrenic patients, i.e. opposite changes in gamma oscillations have been linked to chronic versus psychosis states of the disease. A deficit in gamma power is generally correlated with negative symptoms, whereas an increased propensity for gamma oscillations is found during psychotic episodes and hallucinations [63-67]. Further support for the role of N-methyl-D-aspartate (NMDA) and GABAergic dysregulation in the genesis of perturbed gamma rhythm comes from consistent findings across species. Network oscillation and connectivity in the gamma frequency range can be readily observed, both experimentally and clinically, and may generate essential data concerning the pathophysiological processes underlying the dysfunction in the integrity of glutamatergic, dopaminergic, and GABAergic neuronal circuits in schizophrenia.

Glutamate NMDA receptor antagonists such as PCP, ketamine, and MK- 801 have utility in modeling the positive, negative, and cognitive deficits of schizophrenia in healthy man and laboratory animals [68-72]. In preclinical studies, acute administration of PCP elicited aberrant network oscillations in the higher gamma frequency range [73-75]. A reduction of theta oscillations [76] and functional connectivity observed with PCP [75] correlates with the associated deficit in cognitive process (see fig. 2 for a case study on PCP with risperidone reversal). In the case of ketamine, the enhanced gamma network oscillation was independent of hyperlocomotion [75, 77, 78]. For MK801, the enhanced higher gamma oscillatory activity was associated with peak functional coherent activity in slow $\alpha_{1}$ oscillations in the frontoparietal cortical area $[75,78]$. The effect on slow alpha oscillatory rhythm has been correlated earlier to serotonergic control mechanisms elicited by hallucinogenic drugs such as lysergic acid diethylamide (LSD) and the serotonergic phenethylamine hallucinogen [-]-2,5-dimethoxy-4-methylamphetamine (DOM) [79].

The atypical antipsychotics decreased EEG slow alpha and beta spectral power, especially within the striatum [80], and functional connectivity in slow alpha and higher gamma oscillatory rhythms in multichannel EEG-in- 


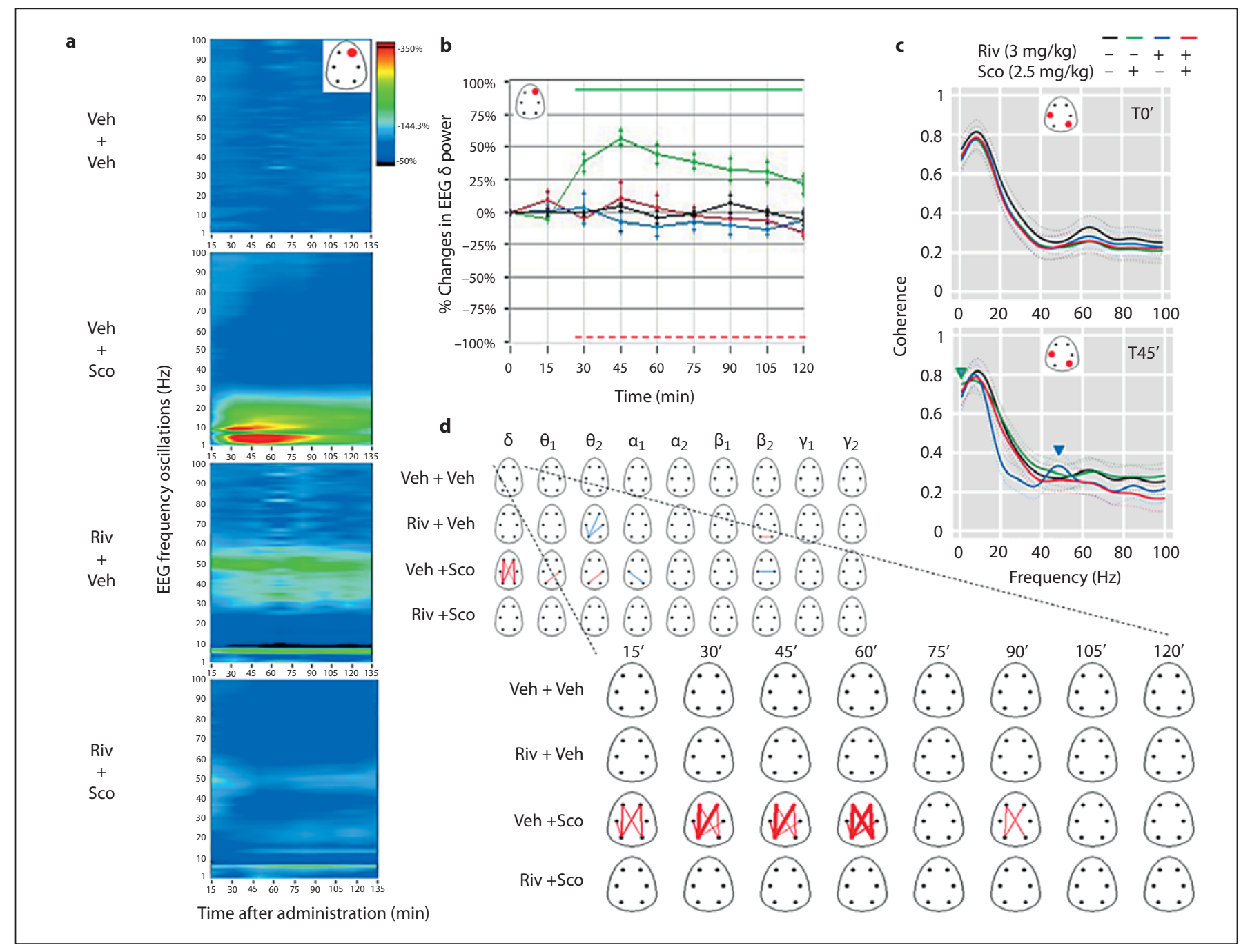

Fig. 1. a Time course of the effects of combined subcutaneous administration of vehicle/vehicle, vehicle/scopolamine $(0.16 \mathrm{mg} / \mathrm{kg})$, rivastigmine $(3 \mathrm{mg} / \mathrm{kg}) /$ vehicle, and rivastigmine $(3 \mathrm{mg} / \mathrm{kg}) / \mathrm{sco}-$ polamine $(0.16 \mathrm{mg} / \mathrm{kg})$ on the EEG spectral patterns in frontoparieto-occipital cortical areas (only the right hemisphere is presented and the red dot on the brain diagram marks the brain region in which the drug effects are displayed, $\mathrm{n}=8$ for each condition) during each 15-min block of the recording session in rats. Mean EEG spectra were expressed as a percentage of the mean spectra in the baseline period. Rivastigmine elicited peak changes in both slow theta $(4.5-6 \mathrm{~Hz})$ and gamma $(32-48 \mathrm{~Hz})$ frequency oscillations, whereas scopolamine enhanced delta power $(0.5-4 \mathrm{~Hz})$ for $2 \mathrm{~h}$ after administration. Changes from baseline are presented as a heat map with cold dark blue to warm red color indicating an order increase in the magnitude of oscillatory power density in particular frequency. $\mathbf{b}$ Changes in the delta frequency power $(0.5-4 \mathrm{~Hz})$ during the first $2 \mathrm{~h}$ after combined subcutaneous administration of rivastigmine and scopolamine (only the right hemisphere is displayed). Color coded bars above and underneath the curves indicate intervals in which oscillatory activity difference differed from vehicle and scopolamine, respectively (mixed-model ANOVA). c Network coherence changes at baseline T0' and at 45 min after pharmacological treatment of scopolamine elicited coherent activity in the delta frequency range in comparison with that of the control group (green arrowhead), whereas rivastigmine enhanced coherent activity in slow theta $(4.5-6 \mathrm{~Hz})$ and gamma $(32-48 \mathrm{~Hz})$ frequency oscillations (blue arrowhead). d Functional network coherence changes from baseline in each frequency band of interest derived from consecutive 4-second epochs concatenated and averaged in the first 15-min block (upper panel). The width of the edges between pair electrodes is drawn proportional to the weight of changes in coherent activity from baseline $(0-50,50-100$, and $100-150 \%)$. Red color represents increases and blue color indicates decreases. Average networks derived from the first session's recording session in each pharmacological condition and for each frequency band of interest: $\delta(0.5-4 \mathrm{~Hz}) ; \theta_{1}(4.5-6 \mathrm{~Hz}) ; \theta_{2}(6.5-8$ $\mathrm{Hz}) ; \alpha_{1}(8.5-11) ; \alpha_{2}(11.5-13) ; \beta_{1}(13.5-18 \mathrm{~Hz}) ; \beta_{2}(18.5-30 \mathrm{~Hz}) ; \gamma_{1}$ (30.5-50 Hz); $\gamma_{2}(50.1-100 \mathrm{~Hz})$. Time-evolving dominant coherent activity in the frontoparietal and occipital structures indicated the potential of rivastigmine to attenuate scopolamine-induced most persistent $\delta$ frequency edges (for further details see Ahnaou et al. [7]). Data: Drinkenburg laboratory. Veh = Vehicle; $\mathrm{Sco}=$ scopolamine; Riv = rivastigmine. 


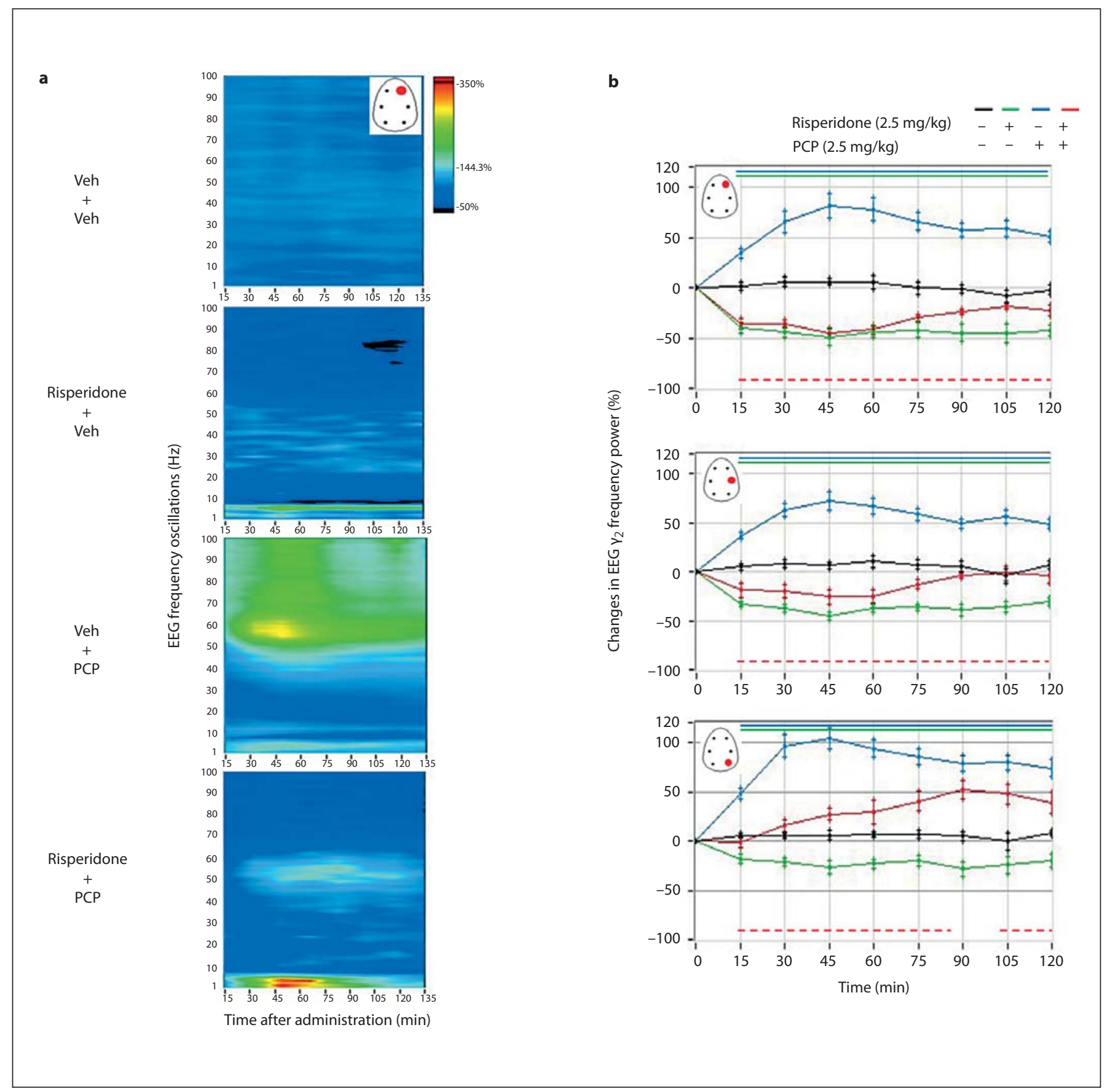

Fig. 2. a Time course effects of combined subcutaneous administration of vehicle/vehicle, vehicle/PCP $(2.5 \mathrm{mg} / \mathrm{kg})$, risperidone $(2.5 \mathrm{mg} / \mathrm{kg}) / \mathrm{vehicle}$, and risperidone $(2.5 \mathrm{mg} / \mathrm{kg}) / \mathrm{PCP}(2.5 \mathrm{mg} / \mathrm{kg})$ on the EEG spectral patterns in fronto-parieto-occipital cortical areas (only the right hemisphere is presented and the red dot on the brain diagram marks the brain region in which the drug effects are displayed; $\mathrm{n}=8$ for each condition) during each 15 -min block of the recording session in rats. Mean EEG spectra were expressed as a percentage of the mean spectra in the baseline period. Peak changes were elicited in higher gamma frequency oscillations for $2 \mathrm{~h}$ after the administration. Changes from baseline are presented as a heat map with cold dark blue to warm red color, indicating an order increase in the magnitude of oscillatory power density in particular frequency. $\mathbf{b}$ Changes in peak gamma 2 frequency (50.1$100 \mathrm{~Hz}$ ) during $2 \mathrm{~h}$ after the combined treatments (only the right hemisphere is displayed, $\mathrm{n}=8$ for each condition). Color coded bars above and underneath the curves indicate intervals in which oscillatory activity difference differed from vehicle and PCP, respectively (mixed-model ANOVA). Risperidone was potent enough to significantly attenuate the aberrant high gamma oscillations in PCP-treated rats. Data: Drinkenburg laboratory. Veh = Vehicle. 
strumented rats [81]. Acute administration of antipsychotics was shown to reduce the rise of EEG gamma power elicited by ketamine [71]. Pretreatment with antipsychotics abolished abnormal cortical network synchrony in the slow alpha frequency range induced by amphetamine and MK801 and in the higher gamma frequency range induced by NMDA antagonists.

In a similar vein, the positive allosteric modulator TASP0433864 or orthosteric agonist at the metabotropic receptor 2 LY379268 completely reversed the ketamineinduced power increase in high-frequency bands [71,81, 82] and partially reversed disrupted coherence [83].

However, a major challenge remains in modeling the negative symptoms of the disease state when blocking NMDA neurotransmission. To ensure optimal translational relevance of the model, chronic administration of ketamine may be more relevant as it closely aligns with the clinical condition of negative symptoms of the disease, which is associated with consistent decreases in gamma oscillations, and functional network connectivity [84].

\section{Dopaminergic Models}

Amphetamine is a widely used psychomotor stimulant for modeling positive symptoms of schizophrenia in rodents, and it is known to elicit prominent motor activity, during which the firing rate of neurons in the hippocampus is rhythmically modulated at a $\sim 8-\mathrm{Hz}$ 'theta rhythm' [85]. Amphetamine mainly induced an increase in EEG power and coherence in the higher theta and alpha bands. Increases in alpha power correlated with increases in locomotor activity $[7,86]$. Pretreatment with the atypical antipsychotic olanzapine consistently attenuated the amphetamine-induced pathological enhancement of oscillations and functional connectivity at the slow alpha frequency range [81].

While it has been proposed that insufficient NMDA-R drive of fast-firing parvalbumin GABA-expressing interneurons is a prime mechanism of the disturbances in gamma oscillations seen in schizophrenics, in addition nonphysiological changes in terms of prolonged entrainment and increased gamma oscillatory activity have also been reported after administration of amphetamine or the dopamine agonist apomorphine, thus emphasizing the intricate relationship between hyperdopaminergia, hypoglutamatergia, and GABA system dysfunction in schizophrenic symptomatology $[87,88]$.

\section{Other Models}

Deregulated levels of excitation and inhibition leading to abnormal EEG network oscillations and connectivity represents an effective strategy to assess the efficacy of novel drugs targeted at strengthening plasticity and interand intrahemispheric connectivity. Perturbations in the mechanisms underlying structural and functional developmental processes have also been useful to test pharmacological responses in disrupted cortico-cortical and cortico-subcortical oscillatory synchrony. For instance, clozapine was effective in reversing the deficit in long-range EEG theta network connectivity between the prefrontal cortex and the hippocampus in rats exposed to maternal immune activation, known as a risk factor for schizophrenia $[89,90]$. Another example is the destabilization of neuronal networks and the increased incidence of epileptiform activity associated with pathologically elevated amyloid beta and the microtubule-binding protein Tau. Seizure phenotype (spikes and sharp waves) is most often noticed in models carrying the Swedish mutation, including Tg2576, APP23, hAPPJ20, APdE9 [91, 92], and apolipoprotein E4 [94], which strongly contribute to impaired functional connectivity across brain regions. Antiepileptic drugs that block sodium channels suppressed neural hyperactivation and epileptiform discharges in APdE9 [95]. The antiepileptic drug levetiracetam effectively suppressed abnormal spiking activity in hAPP mice and reversed their behavioral abnormalities and cognitive impairments [96], whereas cessation of levetiracetam treatment was accompanied by the reappearance of the recurrent aberrant network activity, dysfunctional epileptiform network, and behavioral abnormalities [96]. This potential mechanistic convergence of the effects of elevated amyloid beta and Tau makes EEG networks and functional connectivity strong functional markers for assessing novel disease interception therapeutics.

It is important to note that abnormalities in other EEG frequency bands than theta, alpha, and gamma have been well documented in a number of brain disorders and have been paralleled by preclinical animal disease models. While beyond the scope of this review, it is necessary to highlight the difficulty of parsing out the specific implication of a deficit in oscillations in a single frequency band because of the interdependence of neuronal oscillatory activity in different frequencies such as delta-gamma, thetagamma, and delta-beta cross-frequency coupling [97-99].

\section{Pharmaco-Event-Related Potentials}

ERP and event-related oscillations are extensively used to study the disruption of neuronal circuits underlying sensory encoding, information processing, and attention 
in neuropsychiatric and neurodegenerative disorders. To date, several sensory-level ERP measures, including the auditory P50 paradigm, mismatch negativity (MMN), and P300 responses have been validated in both human clinical investigations and animal models [100-102].

\section{P50 Gating Paradigm}

The ability of the central nervous system to inhibit the response to incoming irrelevant sensory input is a fundamental protective mechanism that prevents the flooding of higher cortical centers with irrelevant information. The auditory paired-stimulus P50 paradigm is a prominent neurophysiological tool used to index preattentive auditory processing underlying stimulus detection. Abnormalities in P50 suppression have been related to dysfunctional auditory information evaluation and speed processing in cognitive tests in $\mathrm{AD}$ and schizophrenic patients [103-105].

Changes in the amplitude of auditory-evoked potential (AEP) responses in humans and animals can be demonstrated in the double click paradigm, in which two identical auditory tones are presented in a time window of $500 \mathrm{~ms}$. Normal subjects have a smaller response to the second stimulus tone (S2) compared to the first stimulus tone (S1), and the ratio measure (S2/S1) is used as a quantitative index of sensory gating. Lower ratio numbers reflect stronger attenuation of irrelevant input and thus better gating capability. Modeling sensory-gating deficits in experimental animals often involves the perturbation of their normal physiological gating processes by the use of different pharmacological challenges (scopolamine, amphetamine, PCP, MK-801, and ketamine).

Scopolamine disrupts sensory gating in rats by increasing N50 amplitude for the S2 stimulus, whereas donepezil reversed such gating deficit index by increasing the N50 amplitude of the S1 stimulus [106].

The translation between animal and human pharmaco-ERP components requires special attention in order to appreciate possible discrepancies in peak latencies and consequent labeling. The methodological approach including epidural versus indwelling electrode positioning can account to a large extent for discrepancies in the definition of the human $\mathrm{P}$ and $\mathrm{N}$ wave equivalents in rodents. Latency differences may also relate to species (e.g. rat versus mouse), but regardless of such differences when using a gating paradigm, for example, one can find a consistent and highly replicable reduction of the amplitude of the S1 stimulus [106]. Again, these AEP discrepancies underline the necessity of careful consideration of choice of methodology and where possible adherence to future

p-EEG Studies in Animals animal guidelines for standardization of p-EEG and pERP use, especially when studies from different research groups are to be compared.

Amphetamine and PCP elicit a reduction in both the amplitude to the first stimulus and the gating index [107109]. Likewise, the dopamine receptor agonist apomorphine dose-dependently reduced the amplitude response to $\mathrm{S} 1$ stimuli and thereby increased the S2/S1 ratio as well as the gating deficit in rats [110]. The antipsychotic clozapine prevented the auditory gating deficits induced by PCP in the CA3, dentate gyrus, and medial prefrontal cortex [111].

The P50 gating deficit models have been useful to characterize the effect of novel drugs and the relevance of novel biological targets. Nicotinic acetylcholinergic receptors (nAChR) have been implicated extensively in human and animal studies of attention, learning, and memory, and are recognized as attractive targets for drug development in cognitive and neurodegenerative disorders. The selective $\alpha_{7}$-nAChR agonist PNU-282987 and the positive allosteric modulator PNU-120596 improved the auditory gating deficit caused by amphetamine in rats $[108,112]$. Likewise the selective $\alpha_{7}$-nicotinic acetylcholine receptor partial agonist JN403 restored the auditory gating deficit in the DBA/2 mouse model [113]. The $\alpha_{4^{-}}$ $\beta_{2}$-nicotine-acetylcholine receptor agonist AZD3480 was useful to reveal the influence of this subunit of the nicotinic receptor on event-related gamma oscillation [114].

Reduced intracellular cAMP and/or cGMP levels in frontal and temporal cortex have been involved in cognitive deficits, suggesting the potential therapeutic utility of phosphodiesterase inhibitors (PDE2, PDE4, PDE5, PDE9, PDE10) for improving cognitive processes [115]. The PDE4 inhibitors RO-20-1724 and rolipram increased the amplitude for the P20 and N40 AEP components, and reversed the disruptive effect of amphetamines on AEP and gating in mice [116]. The PDE2 inhibitor BAY 607550 increased the P1 peak amplitude to S1 stimuli, whereas the PDE10 inhibitor PQ-10 increased the N1 peak amplitude [117], but in our hands PQ-10 failed to prevent disruptive effects of amphetamine and PCP on AEP morphology and aberrant EEG oscillations, which limits interpretation of the procognitive potential of this compound [75].

Similarly, ketamine impaired auditory gating indices and elicited aberrant high-frequency oscillations in rodents [118-120]. This effect was normalized by systemic administration of an antipsychotic or by prior inactivation of the medial septum by the GABA agonist muscimol [120]. 
The P50 gating paradigm has also been used to examine the disruptive effects of other pharmacological challenges, both in neurodevelopmental models of schizophrenia and in transgenic mouse models of AD. For instance, cannabinoid receptors $(\mathrm{CB})$ andendocannabinoids have been linked to psychiatric disorders. The CB1 receptor agonist CP-55940 significantly disrupted auditory gating as well as neuronal theta and gamma network oscillations in the hippocampus and entorhinal cortex in anesthetized and freely moving rats $[121,122]$. In the neonatal ventral hippocampal lesion model of schizophrenia, sensory gating function is impaired and is associated with a prolonged latency from $\mathrm{S} 1$ to $\mathrm{N} 1$ and reduced phase-locked theta and gamma oscillations, particularly at $S 1$ [122, 123]. Finally, in transgenic mouse models of $\mathrm{AD}$, information processing deficits are associated with an altered excitation-inhibition balance in brain-wide neuronal networks. For instance, transgenic mice carrying human APPswe and PS1-A264E transgenes show impaired auditory gating, which is associated with the overproduction of Abeta42 [124], while APPswe/PS1dE9 APdE9 mice display aberrant AEP as reflected by larger cortical and thalamic amplitudes of different AEP components to both S1 and S2 stimuli with a paired stimulus index, indicating that the earliest cortical component $\mathrm{N} 1$ was less suppressed in $\mathrm{AD}$-modeled mice than in wild-type animals [125].

\section{Passive Oddball MMN Paradigm}

MMN is typically measured with a passive oddball and is a neurophysiological index of the ability of the brain to extract relevant information from an irrelevant background, i.e. by comparing the incoming stimuli to a shortlived sensory memory trace of preceding sounds. NMDA receptors have been implicated in the generation of the MMN response and hence the MMN has been proposed as an index of NMDA receptor (dys)function. The nonselective channel blockers of NMDA reliably diminish automatic deviance detection in human subjects as well as in animal models $[126,127]$. Local application of the NMDA antagonist PCP disrupted MMN in the wake monkey auditory cortex in a layer-specific manner [127]. MMN-like activity can be observed in mice in both duration and frequency deviance paradigms [128], and was attenuated by ketamine [129]. In rats, ketamine affected AEP latencies and attenuated deviance by increasing the amplitude to standard stimuli. CP-101,606, a highly selective antagonist at the NR2B subunit of the NMDA receptor, abolished the MMN response by inhibiting the $\mathrm{N} 1$ amplitude of the deviant stimulus [130]. Similarly, in rats the deviance detection associated with MMN-like responses (see fig. 3a, b, c for a case study on MK-801) as well as evoked oscillations (see fig. $3 \mathrm{~d}$ for a case study on MK-801) was dose-dependently affected by MK-801 [131].

\section{Active Oddball P300 Paradigm}

The P300 and P3-like AEP typically measured in an active oddball paradigm is a positive wave in the ERP that occurs $300 \mathrm{~ms}$ or more after the stimulus involving voluntary action after a low-probability, task-relevant stimulus presentation. The P300 and P3-like AEP amplitude has
Fig. 3. a Grand averaged auditory-evoked waveforms recorded from the frontal right electrodes in a passive oddball paradigm with frequency ('pitch') deviants. The auditory-evoked responses (AEP) were recorded during the dark phase in conscious, passive Sprague-Dawley rats, chronically implanted with EEG electrodes. The rats were presented with standard $2-\mathrm{kHz}(80 \%)$ and deviant $4-\mathrm{kHz}(10 \%)$ tones in random order with interstimulus intervals of 5-10 s in separate blocks, before and after subcutaneous administration of MK801 (0.16, 0.64, and $2.5 \mathrm{mg} / \mathrm{kg})$. Poststimuli peaks were determined for the N1 component's amplitude and latency, and for the power of evoked and induced oscillations. The MMN indexes the preattentive stages of short-term memory involved in sensory (auditory) information processing. In the auditory cortex, a detectable change (deviant stimulus) in the physical parameters of a repeated (standard) stimulus evokes a negative component in the auditory, ERP within a 30- to 50-ms time window from stimulus onset-evoked responses in P1, N1, and P2 components to standards, deviants, and those to deviant-standard stimuli after subcutaneous administration of vehicle and MK801 (0.16, 0.64, and 2.5 $\mathrm{mg} / \mathrm{kg}$ ). The open brace indicates a MMN-like response time window obtained for different treatments. Note that MK801 reduced the N1/P2 complex amplitude for both standard and deviant stimuli. Peak mean $( \pm$ SEM) amplitudes $(\mu \mathrm{V} ; \mathbf{b})$ and latencies $(\mathrm{ms} ; \mathbf{c})$ of the N1 component are shown for standards and deviants $(n=8$ for each pharmacological condition). The horizontal lines above the bar graphs mark significance level (black color coded line for standards and red for deviants; linear mixed-model ANOVA). MK801 reduced the amplitudes to both standard and deviant acoustic stimuli, suggesting reduced encoding and discrimination of the sound features during information processing. d Phase-evoked and-induced power time-frequency maps at the occipital left electrode in response to standard and deviant stimuli. Event-related spectral measures were computed on the Morlet wavelet-transformed epochs at each time point and wavelet frequency to yield average time-frequency maps. MK801 enhanced phase-locked slow and high gamma frequency oscillations with the exogenous stimuli (first arrows) followed by induced aberrant gamma oscillations (second arrows). Data: Drinkenburg laboratory.

(For figure see next page.) 
a

$\stackrel{\text { Vehicle }}{-0.16-0.64-2.5}$
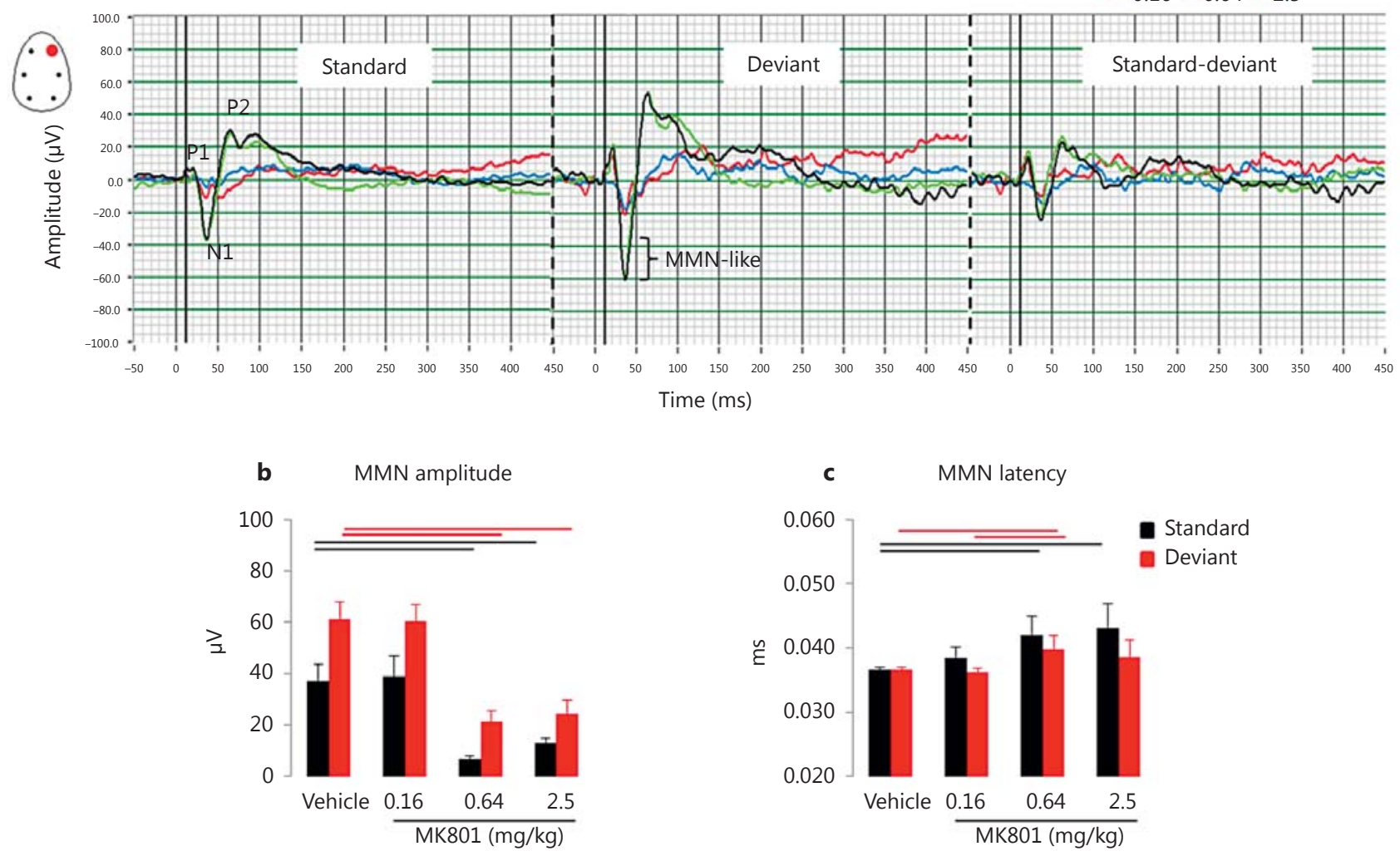

d

.

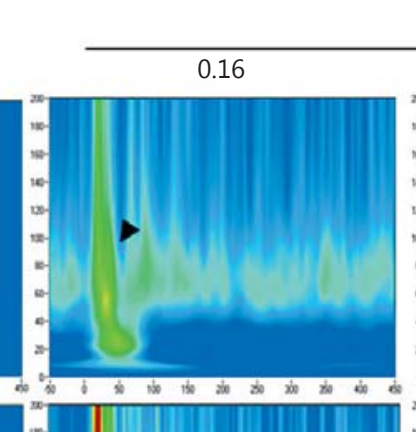

MK801 (mg/kg)
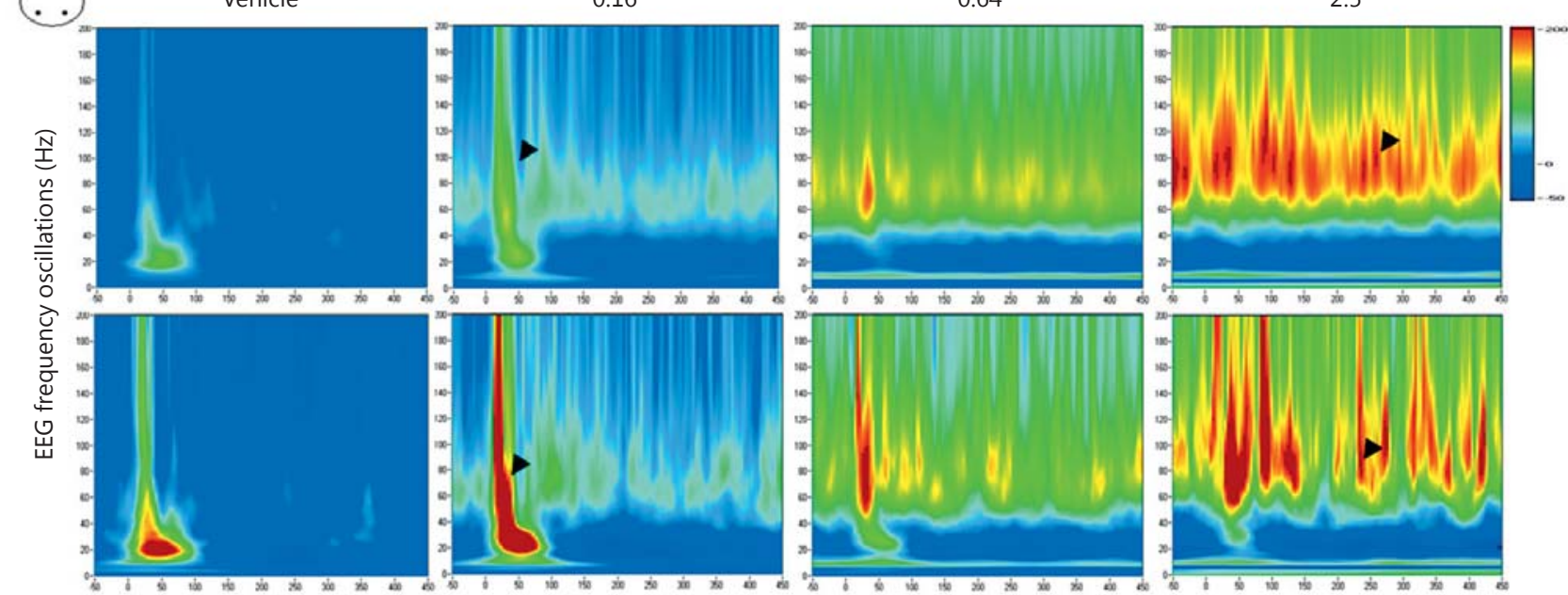

Time (ms) 
been proposed to represent allocation of attentional resources and memory processing [132]. In monkeys, scopolamine prolonged the latency of the late P300-like potentials in the cortex and hippocampus, whereas the novel benzodiazepine inverse agonist S-8510 reversed the scopolamine-induced deficit [133]. Rats performing an active discriminant task displayed larger amplitudes in target trials compared to nontarget trials [134-136], and repeated methamphetamine administration in this model reduced the amplitude of P3-like AEP, indicating that changes in catecholamine transmission may affect the $\mathrm{P} 3$ generation [136], whereas modafinil, a drug used for improving alertness, lowered behavioral performance, decreased P3-like latency, and slightly affected its amplitude [134].

As exemplified above, the growing interest in network oscillations and stimulus-induced changes in sensory processes, which are phylogenetically well conserved, can provide opportunities for designing useful translational biomarkers of functional target engagement and thereby for the discovery of novel therapeutics.

\section{Conclusion}

Animal EEG research has made valuable contributions to neurophysiological science: as animal neurophysiological studies are open to invasive brain recording and stimulation paradigms as well as other in vivo techniques (e.g. multi- or single unit recordings, optogenetics), the neuronal circuits and oscillation-generating systems underlying the EEG can be studied in detail. The use of animal p-EEG has been and still is instrumental in drug discovery and development: it is generally applied to character- ize the functional effect or potential efficacy of test compounds, to assess pharmaco-dynamic characteristics, and to monitor side effects (e.g. sedation) and toxicity (e.g. epileptic seizures). Over the past decade p-EEG has evolved much more as a pharmaco-dynamic biomarker for specific pharmacological activities (e.g. benzodiazepines, glutamatergic compounds, etc.), rather than as a pharmacotherapeutic predictive marker with specificity for every type of treatment efficacy: the translational validity of applications of animal p-EEG and pharmacosleep EEG is dependent on the psychoactivity and/or neuronal substrates under investigation: for studying effects of drugs on sleep-wake and neurocognitive processes, rodent p-EEG has shown high predictive and (back-)translational validity, while reversal of several challenge models has been successfully validated as well.

p-EEG is thus thought to have significant potential as a translatable, intermediate biomarker of central pharmacodynamic activity; however, its full potential could not yet be realized due to poor standardization of methodology, especially between academia and industry research, rendering data pooling and meta-analyses flawed and assessment of translatability problematic [137]. Therefore, the animal p-EEG review papers in this special issue essentially form a prequel to novel IPEG guidelines for animal p-EEG and animal pharmaco-sleep EEG studies ${ }^{1}$.

\footnotetext{
1 Such guidelines are presently being prepared de novo as a follow-up to the IPEG human guidelines which have already appeared [138, 139]: with this paper the IPEG would also like to invite people who think they can further contribute to the formulation of such guidelines to contact the first author.
}

\section{References}

1 Drinkenburg WH: Electroencephalography and pharmaco-electroencephalo-graphy; in Stolerman IP, Price LH (eds): Encyclopedia of Psychopharmacology, ed 2. Springer, Berlin, 2015, pp 592-602.

$>2$ Drinkenburg WH, Ahnaou A: The use of pharmaco-electroencephalography in preclinical models in drug discovery; in Drinkenburg WH, Ruigt G, Jobert M (eds): Essentials and Applications of EEG Research in Preclinical and Clinical Pharmacology. Berlin, UniPublish, 2004, pp 131-148.

$>3$ Uhlhaas PJ, Haenschel C, Nikolić D, Singer $\mathrm{W}$ : The role of oscillations and synchrony in cortical networks and their putative relevance for the pathophysiology of schizophrenia. Schizophr Bull 2008;34:927-943. $\checkmark 4$ Hiyoshi T, Hikichi H, Karasawa J, Chaki S: Metabotropic glutamate receptors regulate cortical gamma hyperactivities elicited by ketamine in rats. Neurosci Lett 2014;567:30-34.

$\checkmark 5$ Hiyoshi T, Kambe D, Karasawa J, Chaki S: Involvement of glutamatergic and GABAergic transmission in MK-801-increased gamma band oscillation power in rat cortical electroencephalograms. Neuroscience 2014;280: 262-274.

$\checkmark 6$ Van der Linde HJ, Van Deuren B, Somers Y, Teisman A, Drinkenburg WH, Gallacher DJ: EEG in the FEAB model: measurement of electroencephalographical burst suppression and seizure liability in safety pharmacology. J Pharmacol Toxicol Meth 2011:63:96-101.
7 Ahnaou A, Huysmans H, Jacobs T, Drinkenburg WH: Cortical EEG oscillations and network connectivity as efficacy indices for assessing drugs with cognition enhancing potential. Neuropharmacology 2014;86:362377

8 Ahnaou A, Langlois X, Steckler T, BartolomeNebreda JM, Drinkenburg WH: Negative versus positive allosteric modulation of metabotropic glutamate receptors (mGluR5): indices for potential pro-cognitive drug properties based on EEG network oscillations and sleepwake organization in rats. Psychopharmacology (Berl) 2015;232:1107-1122.

$>9$ Iosifescu DV: Electroencephalography-derived biomarkers of antidepressant response. Harv Rev Psychiat 2011;19:144-154. 
10 Hunter AM, Cook IA, Leuchter AF: Does prior antidepressant treatment of major depression impact brain function during current treatment? Eur Neuropsychopharmacol 2012;22:711-720.

- 11 Kemp AH, Griffiths K, Felmingham KL, Shankman SA, Drinkenburg W, Arns M, Clark CR, Bryant RA: Disorder specificity despite comorbidity: resting EEG alpha asymmetry in major depressive disorder and posttraumatic stress disorder. Biol Psychol 2010; $85: 350-354$

12 Jeste SS, Frohlich J, Loo SK: Electrophysiological biomarkers of diagnosis and outcome in neurodevelopmental disorders. Curr Opin Neurol 2015;28:110-116.

13 Babiloni C, Infarinato F, Aujard F, Bastlund J F, Bentivoglio M, Bertini G, Del Percio C, Fabene P, Forloni G, Herrero Ezquerro MT, Noè FM, Pifferi F, Ros-Bernal F, Christensen DZ, Dix S, Richardson JC, Lamberty Y, Drinkenburg W, Rossini PM: Effects of pharmacological agents and other challenges on electroencephalographic rhythms in preclinical studies: towards translational models for drug discovery in Alzheimer's disease. Clin Neurophysiol 2013;124:437-451.

14 Babiloni C, Lizio R, Marzano N, Capotosto P, Soricelli A, Triggiani AI, Cordone S, Gesualdo L, Del Percio C: Brain neural synchronization and functional coupling in Alzheimer's disease as revealed by resting state EEG rhythms. Int J Psychophysiol 2015, Epub ahead of print DOI: 10.1016/j.ijpsycho.2015. 02.008 .

15 Vecchio F, Babiloni C, Lizio R, Fallani Fde V, Blinowska K, Verrienti G, Frisoni G, Rossini PM: Resting state cortical EEG rhythms in Alzheimer's disease: toward EEG markers for clinical applications: a review. Suppl Clin Neurophysiol 2013;62:223-236.

16 Beerling W, Koolhaas JM, Ahnaou A, Bouwknecht JA, de Boer SF, Meerlo P, Drinkenburg WH: Physiological and hormonal responses to novelty exposure in rats are mainly related to ongoing behavioral activity. Physiol Behav 2011;103:412-420

$\checkmark 17$ Jobert M, Drinkenburg WHIM, Ahnaou A, Ruigt GSF: Pharmaco-EEG studies in animals: a history-based introduction to contemporary translational applications. Neuropsychobiology 2015;72:139-150.

18 Hasey GM, Kiang M: A review of recent literature employing electroencephalographic techniques to study the pathophysiology, phenomenology, and treatment response of schizophrenia. Curr Psychiatry Rep 2013;15: 388.

19 Leiser SC, Dunlop J, Bowlby MR, Devilbiss DM: Aligning strategies for using EEG as a surrogate biomarker: a review of preclinical and clinical research. Biochem Pharmacol 2011;81:1408-1421.

20 Rossini PM, Del Percio C, Pasqualetti P, Cassetta E, Binetti G, Dal Forno G, Ferreri F, Frisoni G, Chiovenda P, Miniussi C, Parisi L, Tombini M, Vecchio F, Babiloni C: Conver- sion from mild cognitive impairment to $\mathrm{Al}$ zheimer's disease is predicted by sources and coherence of brain electroencephalography rhythms. Neuroscience 2006;143:793-803.

21 Carter CS, Barch DM; CNTRICS Executive Committee: Imaging biomarkers for treatment development for impaired cognition: report of the sixth CNTRICS meeting: biomarkers recommended for further development. Schizophr Bull 2012;38:26-33.

22 Arnaiz E, Almkvist O: Neuropsychological features of mild cognitive impairment and preclinical Alzheimer's disease. Acta Neurol Scand Suppl 2003;179:34-41.

23 Solomon M, Ozonoff SJ, Cummings N, Carter CS: Cognitive control in autism spectrum disorders. Int J Dev Neurosci 2008;26:239247.

24 Vaidya CJ, Stollstorff M: Cognitive neuroscience of attention deficit hyperactivity disorder: current status and working hypotheses. Dev Disabil Res Rev 2008;14:261-267.

25 Dimpfel W: Preclinical data base of pharmaco-specific rat EEG fingerprints (tele-stereoEEG). Eur J Med Res 2003;8:199-207.

26 Dimpfel W: Pharmacological modulation of cholinergic brain activity and its reflection in special EEG frequency ranges from various brain areas in the freely moving rat (tele-stereo-EEG). Eur Neuropsychopharmacol 2005; 15:673-682.

27 Dimpfel W: Pharmacological modulation of dopaminergic brain activity and its reflection in spectral frequencies of the rat electropharmacogram. Neuropsychobiol 2008;58:178-186.

28 Krijzer F, Koopman P, Olivier B: Classification of psychotropic drugs based on pharmaco-electrocorticographic studies in vigilancecontrolled rats. Neuropsychobiol 1993;28: 122-137.

29 Nickel B, Zerrahn H: Pharmaco-electroencephalography in the rat as a method for characterization of different types of analgesics. Postgrad Med J 1987;63(suppl 3):45-47.

30 Cantero JL, Atienza M: The role of neural synchronization in the emergence of cognition across the wake-sleep cycle. Rev Neurosci 2005; 16:69-83.

-31 Kaiser J, Lutzenberger W: Induced gammaband activity and human brain function. Neuroscientist 2003;9:475-484.

32 Lisman J, Buzsáki G: A neural coding scheme formed by the combined function of gamma and theta oscillations. Schizophr Bull 2008;34: 974-980.

33 Singer W: Neuronal synchrony: a versatile code for the definition of relations? Neuron 1999;24:49-65.

34 Babiloni C, Vecchio F, Lizio R, Ferri R, Rodriguez G, Marzano N, Frisoni GB, Rossini PM: Resting state cortical rhythms in mild cognitive impairment and Alzheimer's disease: electroencephalographic evidence. J Alzheimers Dis 2011;26(suppl 3):201-214.

35 Buzsáki G, Watson BO: Brain rhythms and neural syntax: implications for efficient coding of cognitive content and neuropsychiatric disease. Dialog Clin Neurosci 2012;14:345367.

-36 Uhlhaas PJ, Singer W: Abnormal neural oscillations and synchrony in schizophrenia. Nat Rev Neurosci 2010;11:100-113.

37 Cappaert NL, Lopes da Silva FH, Wadman WJ: Spatio-temporal dynamics of theta oscillations in hippocampal-entorhinal slices. Hippocampus 2009;19:1065-1077.

38 Buzsáki G, Wang XJ: Mechanisms of gamma oscillations. Annu Rev Neurosci 2012;35: 203-225.

39 Debener S, Herrmann CS, Kranczioch C, Gembris D, Engel AK: Top-down attentional processing enhances auditory evoked gamma band activity. Neuroreport 2003;14:683-686.

40 Fell J, Klaver P, Lehnertz K, Grunwald T, Schaller C, Elger CE, Fernández G: Human memory formation is accompanied by rhinalhippocampal coupling and decoupling. Nat Neurosci 2001;4:1259-1264.

41 Fries P: Neuronal gamma-band synchronization as a fundamental process in cortical computation. Ann Rev Neurosci 2009;32:209224.

42 Sederberg PB, Kahana MJ, Howard MW, Donner EJ, Madsen JR: Theta and gamma oscillations during encoding predict subsequent recall. J Neurosci 2003;23:10809-10814.

43 Tallon-Baudry C, Bertrand O, Hénaff MA, Isnard J, Fischer C: Attention modulates gamma-band oscillations differently in the human lateral occipital cortex and fusiform gyrus. Cereb Cortex 2005;15:654-662.

44 Jeong J: EEG dynamics in patients with Alzheimer's disease. Clin Neurophysiol 2004; 115:1490-1505.

45 Babiloni C, Binetti G, Cassetta E, Cerboneschi D, Dal Forno G, Del Percio C, Ferreri F, Ferri R, Lanuzza B, Miniussi C, Moretti DV, Nobili F, Pascual-Marqui RD, Rodriguez G, Romani GL, Salinari S, Tecchio F, Vitali P, Zanetti O, Zappasodi F, Rossini PM: Mapping distributed sources of cortical rhythms in mild Alzheimer's disease. A multicentric EEG study. Neuroimage 2004;22:57-67.

46 Jackson CE, Snyder PJ: Electroencephalography and event-related potentials as biomarkers of mild cognitive impairment and mild Alzheimer's disease. Alzheimers Dement 2008;4:S137-S143.

47 Yener GG, Leuchter AF, Jenden D, Read SL, Cummings JL, Miller BL: Quantitative EEG in frontotemporal dementia. Clin Electroencephalogr 1996;27:61-68.

48 Yener GG, Başar E: Brain oscillations as biomarkers in neuropsychiatric disorders: following an interactive panel discussion and synopsis. Suppl Clin Neurophysiol 2013;62: 343-363.

49 Yener GG, Başar E: Biomarkers in Alzheimer's disease with a special emphasis on event-related oscillatory responses. Suppl Clin Neurophysiol 2013;62:237-273.

50 Van Dam D, De Deyn PP: Drug discovery in dementia: the role of rodent models. Nat Rev Drug Discov 2006;5:956-970. 
51 Dringenberg HC, Rubenstein ML, Solty H, Tomaszek S, Bruce A: Electroencephalographic activation by tacrine, deprenyl, and quipazine: cholinergic vs. non-cholinergic contributions. Eur J Pharmacol 2002;447:4350.

52 Ebert U, Kirch W: Scopolamine model of dementia: electroencephalogram findings and cognitive performance. Eur J Clin Invest 1998;28:944-949.

53 Chauvière L, Rafrafi N, Thinus-Blanc C, Bartolomei F, Esclapez M, Bernard C: Early deficits in spatial memory and theta rhythm in experimental temporal lobe epilepsy. J Neurosci 2009;29:5402-5410.

54 Kikuchi M, Wada Y, Nanbu Y, Nakajima A, Tachibana H, Takeda T, Hashimoto T: EEG changes following scopolamine administration in healthy subjects. Quantitative analysis during rest and photic stimulation. Neuropsychobiol 1999;39:219-226.

55 Newman EL, Gillet SN, Climer JR, Hasselmo ME: Cholinergic blockade reduces thetagamma phase amplitude coupling and speed modulation of theta frequency consistent with behavioral effects on encoding. J Neurosci 2013;33:19635-19646.

- 56 Hatayama Y, Hashimoto T, Kohayakawa H, Kiyoshi T, Nakamichi K, Kinoshita T, Yoshida $\mathrm{N}$ : In vivo pharmacological characterization of AC-3933, a benzodiazepine receptor partial inverse agonist for the treatment of Alzheimer's disease. Neuroscience 2014;265: 217-225.

-57 Sambeth A, Riedel WJ, Smits LT, Blokland A: Cholinergic drugs affect novel object recognition in rats: relation with hippocampal EEG? Eur J Pharmacol 2007;572:151-159.

- 58 Siok CJ, Rogers JA, Kocsis B, Hajós M: Activation of alpha7 acetylcholine receptors augments stimulation-induced hippocampal theta oscillation. Eur J Neurosci 2006;23:570574.

-59 Brazhnik ES, Muller RU, Fox SE: Muscarinic blockade slows and degrades the locationspecific firing of hippocampal pyramidal cells. J Neurosci 2003;23:611-621.

-60 Chen CR, Yang SR, Liu YY, Qu WM, Urade Y, Huang ZL: Roles of adrenergic $\alpha_{1}$ and dopamine $\mathrm{D}_{1}$ and $\mathrm{D}_{2}$ receptors in the mediation of the desynchronization effects of modafinil in a mouse EEG synchronization model. PLoS One 2013;8:e76102.

-61 Herrmann CS, Demiralp T: Human EEG gamma oscillations in neuropsychiatric disorders. Clin Neurophysiol 2005;116:27192733.

-62 Gandal MJ, Edgar JC, Klook K, Siegel SJ: Gamma synchrony: towards a translational biomarker for the treatment-resistant symptoms of schizophrenia. Neuropharmacology 2012;62:1504-1518.

-63 Spencer KM: Visual gamma oscillations in schizophrenia: implications for understanding neural circuitry abnormalities. Clin EEG Neurosci 2008;39:65-68.
64 Spencer KM, Nestor PG, Perlmutter R, Niznikiewicz MA, Klump MC, Frumin M, Shenton ME, McCarley RW: Neural synchrony indexes disordered perception and cognition in schizophrenia. Proc Natl Acad Sci USA 2004; 101:17288-17293.

65 Mulert C, Kirsch V, Pascual-Marqui R, McCarley RW, Spencer KM: Long-range synchrony of $\gamma$ oscillations and auditory hallucination symptoms in schizophrenia. Int J Psychophysiol 2011;79:55-63.

66 Tsuchimoto R, Kanba S, Hirano S, Oribe N, Ueno T, Hirano Y, Nakamura I, Oda Y, Miura T, Onitsuka T: Reduced high and low frequency gamma synchronization in patients with chronic schizophrenia. Schizophr Res 2011;133:99-105.

67 Williams LM, Whitford TJ, Nagy M, Flynn G, Harris AW, Silverstein SM, Gordon E: Emotion-elicited gamma synchrony in patients with first-episode schizophrenia: a neural correlate of social cognition outcomes. J Psychiatry Neurosci 2009;34:303-313.

68 Bondi C, Matthews M, Moghaddam B: Glutamatergic animal models of schizophrenia. Curr Pharm Des 2012;18:1593-1604.

-69 Javitt DC, Zukin SR: Recent advances in the phencyclidine model of schizophrenia. Am J Psychiatry 1991;148:1301-1308.

70 Javitt DC, Jayachandra M, Lindsley RW, Specht CM, Schroeder CE: Schizophrenialike deficits in auditory $\mathrm{P} 1$ and N1 refractoriness induced by the psychomimetic agent phencyclidine (PCP). Clin Neurophysiol 2000;111:833-836.

71 Jones NC, Reddy M, Anderson P, Salzberg MR, O'Brien TJ, Pinault D: Acute administration of typical and atypical antipsychotics reduces EEG $\gamma$ power, but only the preclinical compound LY379268 reduces the ketamineinduced rise in $\gamma$ power. Int J Neuropsychopharmacol 2012;15:657-668.

72 Meltzer HY, Rajagopal L, Huang M, Oyamada Y, Kwon S, Horiguchi M: Translating the $\mathrm{N}$-methyl-D-aspartate receptor antagonist model of schizophrenia to treatments for cognitive impairment in schizophrenia. Int $\mathrm{J}$ Neuropsychopharmacol 2013;16:2181-2194.

73 Sebban C, Tesolin-Decros B, Ciprian-Ollivier J, Perret L, Spedding M: Effects of phencyclidine (PCP) and MK 801 on the EEGq in the prefrontal cortex of conscious rats; antagonism by clozapine, and antagonists of AMPA-, $a_{1}$ - and 5- $\mathrm{HT}_{2 \mathrm{~A}}$-receptors. Br J Pharmacol 2002;135:65-78.

74 Ma J, Leung LS: Relation between hippocampal gamma waves and behavioral disturbances induced by phencyclidine and methamphetamine. Behav Brain Res 2000;111:1-11.

75 Ahnaou A, Huysmans H, Drinkenburg WHIM: Cortical gamma network oscillations and connectivity: a neurophysiological target for assessing drugs with antipsychotic potential. Schizophr Bull. Submitted.
76 Mattia A, Moreton JE: Electroencephalographic (EEG), EEG power spectra, and behavioral correlates in rats given phencyclidine. Neuropharmacology 1986;25:763-769.

77 Hakami T, Jones NC, Tolmacheva EA, Gaudias J, Chaumont J, Salzberg M, O'Brien TJ, Pinault D: NMDA receptor hypofunction leads to generalized and persistent aberrant gamma oscillations independent of hyperlocomotion and the state of consciousness. PLoS One 2009;4:e6755.

78 Pinault D: N-methyl D-aspartate receptor antagonists ketamine and MK-801 induce wakerelated aberrant gamma oscillations in the rat neocortex. Biol Psychiatry 2008;63:730-735.

79 Dimpfel W, Spüler M, Nichols DE: Hallucinogenic and stimulatory amphetamine derivatives: fingerprinting DOM, DOI, DOB, MDMA, and MBDB by spectral analysis of brain field potentials in the freely moving rat (tele-stereo-EEG). Psychopharmacology 1989;98:297-303.

-80 Dimpfel W: Characterization of atypical antipsychotic drugs by a late decrease of striatal alphal spectral power in the electropharmacogram of freely moving rats. Br J Pharmacol 2007;152:538-548.

81 Ahnaou A, Biermans R, Drinkenburg WHIM: Modulation of mGlu2 receptors, but not PDE10A inhibition normalizes pharmacologically-induced deviance in auditory evoked potentials and oscillations in conscious rats. PLoS One 2016; 11: e0147365.

-82 Hiyoshi T, Marumo T, Hikichi H, Tomishima Y, Urabe H, Tamita T, Iida I, Yasuhara A, Karasawa J, Chaki S: Neurophysiologic and antipsychotic profiles of TASP0433864, a novel positive allosteric modulator of metabotropic glutamate 2 receptor. J Pharmacol Exp Ther 2014;351:642-653.

\$83 Fujáková M, Páleníček T, Brunovský M, Gorman I, Tylš F, Kubešová A, Ř́pová D, Krajča V, Horáček J: The effect of $((-)$-2-oxa-4-aminobicyclo[3.1.0] hexane-2,6-dicarboxylic acid (LY379268), an mGlu2/3 receptor agonist, on EEG power spectra and coherence in ketamine model of psychosis. Pharmacol Biochem Behav 2014;122:212-221.

84 Kittelberger K, Hur EE, Sazegar S, Keshavan V, Kocsis B: Comparison of the effects of acute and chronic administration of ketamine on hippocampal oscillations: relevance for the NMDA receptor hypofunction model of schizophrenia. Brain Struct Funct 2012;217:395-409.

85 Vanderwolf $\mathrm{CH}$ : Hippocampal electrical activity and voluntary movement in the rat. Electroencephalogr Clin Neurophysiol 1969; 26:407-418.

86 Páleníček T, Fujáková M, Brunovský M, Horáček J, Gorman I, Balíková M, Rambousek L, Syslová K, Kačer P, Zach P, Bubeníková-Valešová $\mathrm{V}$, Tylš $\mathrm{F}$, Kubešová $\mathrm{A}$, Puskarčíková J, Höschl C: Behavioral, neurochemical and pharmaco-EEG profiles of the psychedelic drug 4-bromo-2,5-dimethoxyphenethylamine (2C-B) in rats. Psychopharmacology 2013;225:75-93. 
87 Berke JD: Fast oscillations in cortical-striatal networks switch frequency following rewarding events and stimulant drugs. Eur J Neurosci 2009;30:848-859.

$\checkmark 88$ Brown JT, Davies CH, Randall AD: Synaptic activation of $\mathrm{GABA}(\mathrm{B})$ receptors regulates neuronal network activity and entrainment. Eur J Neurosci 2007;25:2982-2990.

89 Dickerson DD, Wolff AR, Bilkey DK: Abnormal long-range neural synchrony in a maternal immune activation animal model of schizophrenia. J Neurosci 2010;30:1242412431.

-90 Dickerson DD, Restieaux AM, Bilkey DK: Clozapine administration ameliorates disrupted long-range synchrony in a neurodevelopmental animal model of schizophrenia. Schizophr Res 2012;135:112-115.

-91 Bezzina C, Verret L, Juan C, Remaud J, Halley H, Rampon C, Dahan L: Early onset of hypersynchronous network activity and expression of a marker of chronic seizures in the Tg2576 mouse model of Alzheimer's disease. PLoS One 2015;10:e0119910.

-92 Palop JJ, Chin J, Roberson ED, Wang J, Thwin MT, Bien-Ly N, Yoo J, Ho KO, Yu GQ, Kreitzer A, Finkbeiner S, Noebels JL, Mucke L: Aberrant excitatory neuronal activity and compensatory remodeling of inhibitory hippocampal circuits in mouse models of Alzheimer's disease. Neuron 2007;55:697-711.

-93 Vogt DL, Thomas D, Galvan V, Bredesen DE, Lamb BT, Pimplikar SW: Abnormal neuronal networks and seizure susceptibility in mice overexpressing the APP intracellular domain. Neurobiol Aging 2011;32:1725-1729.

\$4 Hunter JM, Cirrito JR, Restivo JL, Kinley RD, Sullivan PM, Holtzman DM, Koger D, Delong C, Lin S, Zhao L, Liu F, Bales K, Paul SM: Emergence of a seizure phenotype in aged apolipoprotein epsilon 4 targeted replacement mice. Brain Res 2012;1467:120-132.

-95 Ziyatdinova S, Gurevicius K, Kutchiashvili N, Bolkvadze T, Nissinen J, Tanila H, Pitkänen A: Spontaneous epileptiform discharges in a mouse model of Alzheimer's disease are suppressed by antiepileptic drugs that block sodium channels. Epilepsy Res 2011;94:75-85.

-96 Sanchez PE, Zhu L, Verret L, Vossel KA, Orr AG, Cirrito JR, Devidze N, Ho K, Yu GQ, Palop JJ, Mucke L: Levetiracetam suppresses neuronal network dysfunction and reverses synaptic and cognitive deficits in an Alzheimer's disease model. Proc Natl Acad Sci USA 2012;109:E2895-E2903.

\$97 Allen EA, Liu J, Kiehl KA, Gelernter J, Pearlson GD, Perrone-Bizzozero NI, Calhoun VD: Components of cross-frequency modulation in health and disease. Front Syst Neurosci 2011;5:1-16.

-98 Caixeta FV, Cornélio AM, Scheffer-Teixeira $\mathrm{R}$, Ribeiro $\mathrm{S}$, Tort AB: Ketamine alters oscillatory coupling in the hippocampus. Sci Rep 2013;3:2348.

p-EEG Studies in Animals
\$9 Drago V, Babiloni C, Bartrés-Faz D, Caroli A, Bosch B, Hensch T, Didic M, Klafki HW, Pievani M, Jovicich J, Venturi L, Spitzer P, Vecchio F, Schoenknecht P, Wiltfang J, Redolfi A, Forloni G, Blin O, Irving E, Davis C, Hårdemark HG, Frisoni GB: Disease tracking markers for Alzheimer's disease at the prodromal (MCI) stage. J Alzheimers Dis 2011;26(suppl 3):159-199.

100 Başar E, Başar-Eroğlu C, Güntekin B, Yener GG: Brain's alpha, beta, gamma, delta, and theta oscillations in neuropsychiatric diseases: proposal for biomarker strategies. Suppl Clin Neurophysiol 2013;62:19-54.

-101 Başar E, Başar-Eroğlu C, Ozerdem A, Rossini PM, Yener GG: Application of brain oscillations in neuropsychiatric diseases: a new land? Preface. Suppl Clin Neurophysiol 2013;62:v-vi.

102 Cromwell HC, Mears RP, Wan L, Boutros $\mathrm{NN}$ : Sensory gating: a translational effort from basic to clinical science. Clin EEG Neurosci 2008;39:69-72.

103 Thomas C, vom Berg I, Rupp A, Seidl U, Schröder J, Roesch-Ely D, Kreisel SH, Mundt C, Weisbrod M: P50 gating deficit in Alzheimer dementia correlates to frontal neuropsychological function. Neurobiol Aging 2010;31:416-424.

104 Cancelli I, Cadore IP, Merlino G, Valentinis L, Moratti U, Bergonzi P, Gigli GL, Valente $\mathrm{M}$ : Sensory gating deficit assessed by $\mathrm{P} 50 / \mathrm{Pb}$ middle latency event related potential in $\mathrm{Alz}$ heimer's disease. Clin Neurophysiol 2006; 23:421-425.

105 Javitt DC, Freedman R: Sensory processing dysfunction in the personal experience and neuronal machinery of schizophrenia. Am J Psychiatry 2015;172:17-31.

106 Klinkenberg I, Sambeth A, Blokland A: Cholinergic gating of hippocampal auditory evoked potentials in freely moving rats. Eur Neuropsychopharmacol 2013;23:988-997.

107 de Bruin NM, Ellenbroek BA, Cools AR, Coenen AM, van Luijtelaar EL: Differential effects of ketamine on gating of auditory evoked potentials and prepulse inhibition in rats. Psychopharmacology 1999;142:9-17.

108 Hurst RS, Hajós M, Raggenbass M, Wall TM, Higdon NR, Lawson JA, RutherfordRoot KL, Berkenpas MB, Hoffmann WE, Piotrowski DW, Groppi VE, Allaman G, Ogier R, Bertrand S, Bertrand D, Arneric SP: A novel positive allosteric modulator of the alpha7 neuronal nicotinic acetylcholine receptor: in vitro and in vivo characterization. J Neurosci 2005;25:4396-4405.

109 Maxwell CR, Kanes SJ, Abel T, Siegel SJ: Phosphodiesterase inhibitors: a novel mechanism for receptor-independent antipsychotic medications. Neuroscience 2004;129: 101-107.

110 Breier MR, Lewis B, Shoemaker JM, Light GA, Swerdlow NR: Sensory and sensorimotor gating-disruptive effects of apomorphine in Sprague Dawley and Long Evans rats. Behav Brain Res 2010;208:560-565.
111 Dissanayake DW, Zachariou M, Marsden CA, Mason R: Effects of phencyclidine on auditory gating in the rat hippocampus and the medial prefrontal cortex. Brain Res 2009; 1298:153-160.

112 Hajós M, Hurst RS, Hoffmann WE, Krause M, Wall TM, Higdon NR, Groppi VE: The selective alpha7 nicotinic acetylcholine receptor agonist PNU-282987 [N-[(3R)-1-azabicyclo[2.2.2] oct-3-yl]-4-chlorobenzamide hydrochloride] enhances GABAergic synaptic activity in brain slices and restores auditory gating deficits in anesthetized rats. J Pharmacol Exp Ther 2005;312:1213-1222.

113 Feuerbach D, Lingenhoehl K, Olpe HR, Vassout A, Gentsch C, Chaperon F, Nozulak J, Enz A, Bilbe G, McAllister K, Hoyer D: The selective nicotinic acetylcholine receptor alpha7 agonist JN403 is active in animal models of cognition, sensory gating, epilepsy and pain. Neuropharmacol 2009;56:254-263.

114 Featherstone RE, Phillips JM, Thieu T, Ehrlichman RS, Halene TB, Leiser SC, Christian E, Johnson E, Lerman C, Siegel SJ: Nicotine receptor subtype-specific effects on auditory evoked oscillations and potentials. PLoS One 2012;7:e39775.

115 Heckman PR, Wouters C, Prickaerts J: Phosphodiesterase inhibitors as a target for cognition enhancement in aging and Alzheimer's disease: a translational overview. Curr Pharm Des 2015;21:317-331.

116 Halene TB, Siegel SJ: Antipsychotic-like properties of phosphodiesterase 4 inhibitors: evaluation of 4-(3-butoxy-4-methoxybenzyl)-2-imidazolidinone (RO-20-1724) with auditory event-related potentials and prepulse inhibition of startle. J Pharmacol Exp Ther 2008;326:230-239.

117 Reneerkens OA, Sambeth A, Blokland A, Prickaerts J: PDE2 and PDE10, but not PDE5, inhibition affect basic auditory information processing in rats. Behav Brain Res 2013;250:251-256.

118 Amann LC, Halene TB, Ehrlichman RS, Luminais SN, Ma N, Abel T, Siegel SJ: Chronic ketamine impairs fear conditioning and produces long-lasting reductions in auditory evoked potentials. Neurobiol Dis 2009;35: 311-317.

119 Ehrlichman RS, Gandal MJ, Maxwell CR, Lazarewicz MT, Finkel LH, Contreras D, Turetsky BI, Siegel SJ: N-methyl-D-aspartic acid receptor antagonist-induced frequency oscillations in mice recreate pattern of electrophysiological deficits in schizophrenia. Neuroscience 2009;158:705-712.

120 Ma J, Tai SK, Leung LS: Ketamine-induced deficit of auditory gating in the hippocampus of rats is alleviated by medial septal inactivation and antipsychotic drugs. Psychopharmacology 2009;206:457-467.

121 Hajós M: Targeting information-processing deficit in schizophrenia: a novel approach to psychotherapeutic drug discovery. Trends Pharmacol Sci 2006;27:391-398. 
122 Romero-Pimentel AL, Vázquez-Roque RA, Camacho-Abrego I, Hoffman KL, Linares P, Flores G, Manjarrez E: Histological correlates of N40 auditory evoked potentials in adult rats after neonatal ventral hippocampal lesion: animal model of schizophrenia. Schizophr Res 2014;159:450-457.

123 Vohs JL, Chambers RA, Krishnan GP, O'Donnell BF, Hetrick WP, Kaiser ST, Berg S, Morzorati SL: Auditory sensory gating in the neonatal ventral hippocampal lesion model of schizophrenia. Neuropsychobiology 2009;60:12-22.

124 Wang J, Ikonen S, Gurevicius K, Van Groen $\mathrm{T}$, Tanila H: Altered auditory-evoked potentials in mice carrying mutated human amyloid precursor protein and presenilin-1 transgenes. Neuroscience 2003;116:511517.

125 Gurevicius K, Lipponen A, Tanila H: Increased cortical and thalamic excitability in freely moving APPswe/PS1dE9 mice modeling epileptic activity associated with $\mathrm{Al}$ zheimer's disease. Cereb Cortex 2013;23: 1148-1158.

126 Umbricht D, Koller R, Vollenweider FX, Schmid L: Mismatch negativity predicts psychotic experiences induced by NMDA receptor antagonist in healthy volunteers. Biol Psychiatry 2002;51:400-406.

127 Javitt DC, Steinschneider M, Schroeder CE, Arezzo JC: Role of cortical N-methyl-D-aspartate receptors in auditory sensory memory and mismatch negativity generation: implications for schizophrenia. Proc Natl Acad Sci USA 1996;93:11962-119710.
128 Umbricht D, Vyssotki D, Latanov A, Nitsch R, Lipp HP: Deviance-related electrophysiological activity in mice: is there mismatch negativity in mice? Clin Neurophysiol 2005; 116:353-363.

129 Ehrlichman RS, Maxwell CR, Majumdar S, Siegel SJ: Deviance-elicited changes in event-related potentials are attenuated by ketamine in mice. J Cogn Neurosci 2008;20: 1403-1414.

130 Sivarao DV, Chen P, Yang Y, Li YW, Pieschl $\mathrm{R}$, Ahlijanian MK: NR2B antagonist CP101,606 abolishes pitch-mediated deviance detection in awake rats. Front Psychiatry 2014;5:96.

131 Tikhonravov D, Neuvonen T, Pertovaara A, Savioja K, Ruusuvirta T, Näätänen R, Carlson S: Effects of an NMDA-receptor antagonist MK-801 on an MMN-like response recorded in anesthetized rats. Brain Res 2008; 1203:97-102.

132 Polich J: Updating P300: an integrative theory of P3a and P3b. Clin Neurophysiol 2007; 118:2128-2148.

133 Abe K, Sawada T, Horiuchi M, Yoshimura K: Effects of S-8510, a benzodiazepine receptor partial inverse agonist, on event-related potentials (P300) in monkeys. Psychopharmacology 1999;141:71-76.

134 Grupe M, Grunnet M, Laursen B, Bastlund JF: Neuropharmacological modulation of the P3-like event-related potential in a rat two-tone auditory discrimination task with modafinil and NS9283, a positive allosteric modulator of $\alpha_{4} \beta_{2}$ ChRs. Neuropharmacology 2014;79:444-455.
35 Hattori M, Onoda K, Sakata S: Identification of rat P3-like processes in the anterior cingulate cortex and hippocampus. Neurosci Lett 2010;472:43-46.

136 Takeuchi S, Jodo E, Suzuki Y, Matsuki T, Niwa S, Kayama Y: Effects of repeated administration of methamphetamine on P3like potentials in rats. Int J Psychophysiol 1999;32:183-192.

137 Wilson FJ, Leiser SC, Ivarsson M, Christensen SR, Bastlund JF: Can pharmaco-electroencephalography help improve survival of central nervous system drugs in early clinical development? Drug Discov Today 2014; 19:282-288.

138 Jobert M, Wilson FJ, Ruigt GSF, Brunovsky M, Prichep LS, Drinkenburg WH; IPEG Pharmaco-EEG Guidelines Committee: Guidelines for the recording and evaluation of pharmaco-EEG data in man - the International Pharmaco-EEG Society (IPEG). Neuropsychobiology 2012;66:201-220.

139 Jobert M, Wilson FJ, Roth T, Ruigt GSF, Anderer P, Drinkenburg WH, Bes FW, Brunovsky M, Danker-Hopfe H, Freeman J, van Gerven JM,Gruber G, Kemp B, Klösch G, Ma J, Penzel T, Peterson BT, Schulz H, Staner L, Saletu B, Svetnik V; IPEG Pharmaco-EEG Guidelines Committee: guidelines for the recording and evaluation of pharmaco-sleep studies in man - the International Pharmaco-EEG Society (IPEG). Neuropsychobiology 2013;67:127-167. 